\title{
COMPARISON OF INTELLIGENGE QUOTIENT OF SCHIZOPHRENIC PATIENTS WITH THOSE OF NORMAL POPULATION
}

\author{
Khattri JB', Goit BK², Subedi $A^{1}$
}

${ }^{1}$ Department of Psychiatry, Manipal College of Medical Sciences, Pokhara, Nepal,

${ }^{2}$ Department of Psychiatry, National Medical College, Birgunj, Nepal.

\begin{abstract}
An intelligence deficit in schizophrenia is common and is associated with relapse and occupational impairment. The study aims to examine the intelligence quotient of schizophrenic patients and to compare with those of general population. This was a case control study where 30 adult schizophrenic patients between 15 to 45 years were enrolled from the inpatient and outpatient Psychiatry Department of Manipal College of Medical Sciences, Pokhara, Nepal. For control group, 30 normal subjects were enrolled from the general population matched with case group. The intelligence quotients were assessed by Wechsler Adult Intelligence Scale. The prevalence of intelligence deficit was $76.7 \%$ in the schizophrenic patients. The mean intelligence quotient was 84.80 with standard deviation of 6.53 in patients with schizophrenia. The intelligence quotient was average or above average in all the general populations. The mean intelligence quotient was 110.63 with standard deviation of 8.74 in the general population. The study concluded that the schizophrenic patients performed poorer in intelligence quotient than the general population.
\end{abstract}

\section{KEYWORDS}

IQ, Nepal, schizophrenia,

Wechsler Adult Intelligence Scale

\section{CORRESPONDING AUTHOR}

Dr. Jai Bahadur Khattri

Department of Psychiatry,

Manipal College of Medical Sciences,

Pokhara, Nepal

Email: jai2062@gmail.com

ORCID ID: 0000-0002-6159-4039

DOI: https://doi.org10.3126/nmcj.v21i4.27613 


\section{INTRODUCTION}

Schizophrenia is a mental disorder characterized in general by fundamental and characteristic distortions of thinking and perception, and by inappropriate or blunted affect. Clear consciousness and intellectual capacity are usually maintained, although some cognitive deficits may evolve in the course of time. ${ }^{1}$

Impairment in a variety of cognitive functions is found in patients with schizophrenia. These impairments affect a wide range of cognitive abilities as compared to healthy individuals. Cognitive impairments appear to be present across the lifespan, detectable at the time of the first treatment episode, if not before, and to manifest a generally stable course over time. ${ }^{2}$ Earlier term for schizophrenia called 'dementia praecox' also indicates the central cognitive impairment of this disorder. ${ }^{3,4}$

There is currently no comprehensive theory regarding the nature of this relationship between intelligence and schizophrenia with the available research in this area. The reason might be due to abundance of contradictory results. Many of the earlier studies of schizophrenia were conducted to determine whether persons suffering from the disorder manifested deficits in intelligence quotient (IQ). Few studies published in the past have addressed this question. ${ }^{5}$

Intellectual impairment in schizophrenia affects the course, outcome, and quality of life of the patient significantly and thus need adequate attention in the management of schizophrenia. The objective of this study was to study the intelligence quotient of schizophrenic patients and to compare with those from the general population. Assessment of IQ helps to predict the negative impact of the disorder on the future behaviour and social functioning of the individual. The research question of this study was "Do schizophrenic patients differ from general population in IQ?”

\section{MATERIALS AND METHODS}

This case control study was conducted for three months (from February 2019 to April 2019). The ethical clearance for this study was taken from Institutional Review Committee of Manipal College of Medical Sciences, Pokhara, Nepal. The sample of 30 adult drug naive patients between the ages of 15 to 45 years who had fulfilled the diagnostic criteria of schizophrenia according to ICD-10 criteria $^{1}$ was selected as cases by simple random method. They were enrolled from the inpatient and outpatient Psychiatry Department of Manipal Teaching Hospital, Pokhara, Nepal. The
30 normal subjects (matched with the cases)were enrolled from community for the control group. If patients and control group had any other comorbid psychiatric and/or physical illness which affected cognitive functioning they were excluded from the study and also those from control group who had positive family history of schizophrenia were excluded from the study. The consent was taken from both groups. The consent was taken from first-degree relatives if the patient was unable to give consent. The intelligence quotient of the respondents was measured by Wechsler Adult Intelligence Scale (WAIS). ${ }^{6}$ WAIS is the best standardized and most widely used intelligence test. It was constructed by David Weschler at New York University Medical Centre and Bellivue Psychiatric Hospital. It has undergone several revisions and has 6 verbal test and 5 performance tests.

The statistical methods used in the present study were mean, percentage and chi-square test. The data was considered significant if $\mathrm{p}$ value was less than 0.05 .

\section{RESULTS}

Table 1: Classification of IQ of case and control group. $(\mathrm{n}=60)$

\begin{tabular}{|lccc|} 
IQ & Case (\%) & Control (\%) & p value \\
Mental & $1(3.3)$ & 0 & \\
Defective & B & & \\
Borderline & $6(20)$ & 0 & \\
Dull Normal & $16(53.3)$ & 0 & $<0.001$ \\
Average & $7(23.3)$ & $14(46.7)$ & \\
Bright & 0 & $12(40.0)$ & \\
Normal & 0 & $4(13.3)$ & \\
Superior & 0 & $30(100.0)$ & \\
Total & $\mathbf{3 0 ( 1 0 0 . 0 )}$ & \\
\hline
\end{tabular}

Table 1 shows the classification of IQ between the cases and control group. The 23 cases (76.7\%) performed below average and only 7 cases (23.3\%) had an average IQ. None of the cases had bright normal or superior range of IQ. There was no respondent in the control group who fell in the below average level of IQ. Among the control group, $46.7 \%$ had average IQ, $40 \%$ showed bright normal and $13.3 \%$ were superior. The data was statistically significant.

\begin{tabular}{|lllll|}
\multicolumn{2}{|c|}{ Table 2: Mean IQ of case and control group. } \\
\begin{tabular}{|lllll}
$(\mathbf{n}=\mathbf{6 0})$ & & \\
Variables & Group & $\mathbf{n}$ & Mean \pm SD & p value \\
IQ & Case & 30 & $84.80 \pm 6.53$ & \\
& Control & 30 & $110.63 \pm 8.74$ & $<0.001$ \\
\hline
\end{tabular}
\end{tabular}


Table 2 shows the mean IQ of the cases and control. The mean IQ of cases was 84.80 with SD of 6.53. The mean IQ of the controls was 110.63 with SD of 8.74. The difference in IQ between cases and control was statistically significant $(p<0.001)$.

\section{DISCUSSION}

Understanding the extent of intellectual impairments in schizophrenia is important for understanding the etiology of the condition and its likely outcome. This case-control study was conducted in the tertiary care hospital situated in the Gandaki Province of Nepal. WAIS was administered to assess IQ of both cases and control. Only few studies have been conducted around the world as far as IQ of schizophrenic patients is considered. No such type of study has been conducted in Nepal or in South Asia to the best of author's knowledge. The IQ range from 90 to 109 was considered average in the current study.

The result found that $76.7 \%$ of the schizophrenic patients had below average IQ (Table 1). Weickert et al. also reported reduced IQ in about 50\% of the schizophrenic cases. ${ }^{7}$ One study noted that approximately $70 \%$ of patients showed deterioration of IQ. ${ }^{8}$

The study also showed that mean IQ of case was 84.80 with standard deviation of 6.53. This indicates that there was average deficit of approximately 5 points from average in the schizophrenic patients in the Nepalese sample. The deficit in the schizophrenic patients was almost 26 points in the IQ score as compared with the normal population (Table 2). Winder noted an average deficit of 10 IQ points using the Wechsler tests. ${ }^{9}$ Another study found the mean IQ of 97.20 in patients and 109.26 in controls. ${ }^{10}$ Different studies done in schizophrenic patients also showed impairments between 1 and 3 standard deviations below the population mean (equal to 15-45 IQ points). These studies also confirmed that much of this impairment was present from the beginning. ${ }^{11,12}$ The study conducted in Isreal by adjusting the confounding variable like behaviour and social problem reported 4-8 IQ points deficit among schizophrenia patients. ${ }^{13}$ This finding was also consistent with prior longitudinal studies showing evidence of neuropsychological decline in schizophrenia. ${ }^{14-22}$

The review article of 28 studies found average IQ of $96.08 .^{23}$ In another study using WAIS, the average IQ score for 27 schizophrenic patients was 106.6. ${ }^{24}$ Other studies also found that some patients with schizophrenia had normal or even enhanced cognitive function. ${ }^{25-27}$ The result of studies which found normal or high IQ in schizophrenia patients was contradictory with our study findings. The difference in the study findings between different studies could be due to difference in duration of untreated psychosis, cultural background and level of education of the study populations.

Our study carries few limitations. The samples of the populations tested in this study might not represent the total population. However, this study throws important insight about association between intelligence deficit and schizophrenia. This study will definitely contribute better understanding of the patient's impairment and in the clinical management in the Nepalese scenario. The psychotic symptoms of the patient might also have interfered with the study findings. The future research should be done to answer whether low IQ predicts schizophrenia or vice versa. The future studies should also include optimum participants to produce generalization of the findings.

In conclusion, the intelligence deficits occur significantly in the patients with schizophrenia as compared to the general population. Special social skill training and rehabilitation measures based upon their IQ assessment should be undertaken in the long term treatment of schizophrenia in the Nepalese context.

\section{ACKNOWLEDGEMENT}

The authors would like to thank all participants who volunteered for the study.

\section{REFERENCES}

1. World Health Organization. The ICD-10 Classification of Mental and Behavioral disorders (Tenth Revision): Diagnostic Criteria for Research. Geneva; WHO: 1992.

2. Gelder MG Andreasen NC, Lopez-Ibor Jr JJ, Geddes JR. New Oxford Textbook of Psychiatry. $2^{\text {nd }}$ Edition. Oxford; Oxford University Press: 2009.

3. Sadock BJ, Sadock VA, Ruiz P. Kaplan \& Sadock's Comprehensive Textbook of Psychiatry. $9^{\text {th }}$ Edition. Philadelphia; Lippincott Williams \& Wilkins: 2009.

4. David AS, Fleminger S, Kopelman MD, Lovestone S, Mellers JDC. Lishman's Organic Psychiatry A Textbook of Neuropsychiatry. $4^{\text {th }}$ Edition. UK; Wiley Blackwell: 2009.

5. Aylward E, Walker E, Bettes B. Intelligence in Schizophrenia: Meta-Analysis of the Research. Schizophr Bull 1984; 10: 430-59.

6. Wechsler D. The Measurement and Appraisal of Adult Intelligence. $4^{\text {th }}$ Edition. Baltimore (MD); Williams \& Witkins: 1958. 
7. Weickert TW, Goldberg TE, Gold JM, Bigelow LB, Egan MF, Weinberger DR. Cognitive impairments in patients displaying preserved and compromised intellect. Arch Gen Psychiatr 2000; 57: 907-13.

8. Ohi K, Sumiyoshi C, Fujino $\mathrm{H}$ et al. A Brief Assessment of intelligence Decline in Schizophrenia As Represented by the Difference between Current and Premorbid intellectual Quotient. Front Psychiatr 2017; 8: 293.

9. Winder C. Some psychological studies of schizophrenics. In Jackson D, editor. The Etiology of Schizophrenia. New York: Basic Books 1960: 21678.

10. Hedman AM, van Haren NEM, van Baal CGM, Kahn RS, Hulshoff Pol HE. IQ change over time in schizophrenia and healthy individuals: A metaanalysis. Schizophr Res 2013; 146: 201-8.

11. Heinrichs RW, Zakzanis KK. Neurocognitive deficit in schizophrenia: a quantitative review of the evidence. Neuropsychol 1998; 12: 426-45.

12. Bilder RM, Goldman RS, Volavka J et al. Neurocognitive effects of clozapine, olanzapine, risperidone, and haloperidol in patients with chronic schizophrenia or schizophrenic disorder. Am J Psychiatry 2002; 159: 1018-28.

13. Reichenberg A, Weiser M, Rabinowitz J et al. A population-based cohort study of premorbid intellectual, language, and behaviour functioning in patients with schizophrenia, schizoaffective disorder, and nonpsychotic bipolar disorder. Am J Psychiatry 2002; 159: 2027-35.

14. Kremen WS, Vinogradov S, Poole JH et al. Cognitive decline in schizophrenia from childhood to midlife: A 33-year longitudinal birth cohort study. Schizophr Res 2010; 118: 1-5.

15. Seidman LJ, Buka SL, Goldstein JM, Tsuang MT. Intellectual decline in schizophrenia: Evidence from a prospective birth cohort 28 year follow-up study. J Clin Exp Neuropsychol 2006; 28: 225-42.

16. Caspi A, Reichenberg A, Weiser $\mathrm{M}$ et al. Cognitive performance in schizophrenia patients assessed before and following the first psychotic episode. Schizophr Res 2003; 65: 87-94.
17. Schwartzman AE, Douglas VI. Intellectual loss in schizophrenia: Part 1. Can J Psychol 1962; 16: 1-10.

18. Bilder RM, Reiter G, Bates J et al. Cognitive development in schizophrenia: Follow-back from the first episode. J Clin Exp Neuropsychol 2006; 28: 270-82.

19. Gochman PA, Greenstein D, Sporn A et al. IQ stabilization in childhood-onset schizophrenia. Schizophr Res 2005; 77: 271-7.

20. Lubin A, Williams HL, Gieseking CF. Direct measurement of cognitive deficit in schizophrenia. J Consult Psychol 1962; 26: 139-43.

21. Sheitman BB, Murray MG, Snyder JA et al. IQ scores of treatment-resistant schizophrenia patients before and after the onset of the illness. Schizophr Res 2000; 46: 203-7.

22. Rappaport SR, Webb WB. An attempt to study intellectual deterioration by premorbid and psychotic testing. J Consult Psychol 1950; 14: 95-8.

23. Payne R. Cognitive abnormalities. In Eysenck $\mathrm{H}$, editor. Handbook of Abnormal Psychology. London: Pitman Medical Publishing Co. Ltd 1960: 193-261.

24. Pollack M, Woerner M, Klein DF. A comparison of childhood characteristics of schizophrenics, personality disorders, and their siblings. In Roff $\mathrm{M}$ and Ricks D editors. Life History Research in Psychopathology. Minneapolis: University of Minnesota Press 1970: 208-25.

25. Heinrichs W, Ammari N, McDermid Vaz S, Miles A, Muharib E. Above average intellectual ability and functional status in schizophrenia. Schizophr Bull $2011 ; 267$.

26. Kremen WS, Seidman LJ, Faraone SV, Toomey R, Tsuang MT. The paradox of normal neuropsychological function in schizophrenia. $J$ Abnorm Psychol 2000; 109: 743-52.

27. MacCabe JH, Brebion G, Reichenberg A et al. Superior intellectual ability in schizophrenia: neuropsychological characteristics. Neuropsychol 2012; 26: 181-90. 